\title{
Mitgliederversammlung 2020 online
}

Sehr geehrte Damen, sehr geehrte Herren, liebe Mitglieder der DEGUM,

aufgrund der anhaltenden Pandemie sowie des abgesagten Dreiländertreffens wird die diesjährige Mitgliederversammlung online stattfinden. Allein diese Form der Zusammenkunft garantiert uns die notwendige Planungssicherheit, die wir benötigen, um das Vereinsgeschäft auch in diesen schwierigen Zeiten aufrecht zu erhalten. Die Mitgliederversammlung findet am Freitag, dem 23. Oktober 2020 um 17 Uhr statt. Wir laden Sie hiermit herzlich zu diesem Treffen ein. Ihre individuellen Zugangsdaten zur Mitgliederversammlung werden Ihnen per Mail zugestellt. Bitte beachten Sie, dass Ihre Zugangsdaten nicht auf dritte Personen übertragbar sind. Weitere Informationen zur Mitgliederversammlung finden Sie in den kommenden Wochen auf unserer Webseite www.degum.de. 